\title{
2.1 Aspectos teóricos
}

1. Introduçāo; 2. Razões para concentração, 3. Evidência empirica da concentração; 4. Considerações finais.

\section{Concentração bancária no Brasil: uma evidência empírica*}

Martus A.R. Tavares

Mestre em economia pela Faculdade de Economia e Administração da Universidade de São Paulo (FEA/USP) professor-assistente no Departamento de Economia da Universidade Estadual de Londrina.

\section{INTRODUÇÃO}

O Govemo brasileiro, a partir de $1967 / 68$, pôs em prática algumas medidas para concentrar o sistema bancário. Tais medidas foram ratificadas no início da década de 70 , quando da criação da Comissão de Fusão e Incorporação de Empresa (Cofie), em 1971.

As taxas reais de juros haviam-se tornado positivas desde 1965/66, desestimulando o crescimento econômico. O Governo, que assumiu em 1967, diagnosticou a inflação existente nesta data como proveniente dos custos. Sabe-se que, neste tipo de inflação, a taxa de juros tem papel importante. Desta forma, a redução dessa taxa tornou-se questão central para a meta de combate à inflação e retomada do crescimento. Mas, como a redução dos juros justifica a adoção de políticas de concentração?

A rationale das políticas adotadas, a partir de 1967/ 68 , era de que: concentrando o setor bancário, os bancos alcançariam custos operacionais menores - suposta a existência de economia de escala na atividade bancária e isto se traduzia em menores taxas de juros para os tomadores de empréstimos bancários.

O objetivo deste artigo é medir, sob várias formas, - grau de concentração do setor bancário brasileiro. Aceita-se como verdadeira a hipótese de que, a despeito de haver ou não economia de escala e de haver ou não uma relação positiva entre custos operacionais dos bancos comerciais e taxa de juros, aquelas medidas adotadas foram eficientes no que se refere à tentativa de concentrar o setor bancário comercial. ${ }^{1}$
Existem algumas razôes teóricas para se desejar que se ampliem os tamanhos das unidades produtivas. A existência de economia de escala associada a maiores tamanhos de plantas tende a apresentar maior eficiência.

A teoria econômica neoclássica postula que existe um tamanho ótimo de planta e que a este está associado um custo unitário mínimo de produção. No entanto, não existe um consenso entre os especialistas quanto ao que ocorre com os custos a partir deste nível ótimo de produção, ficando inconclusivo se os custos se estabilizam, crescem imediatamente ou crescem somente a partir de um tamanho maior de planta.

No entanto, a evidência empírica nos coloca apenas raramente diante de uma situação em que os custos médios apresentam a forma de $\mathrm{U}^{2}$. Ou seja, o que é mais comum é que os custos médios não tornem a se elevar imediatamente após terem atingido seu mínimo.

Desta forma, se algumas firmas de uma indústria se interessam por ampliar suas escalas de produção além do tamanho mínimo ótimo, isto só poderá ser feito, dado o tamanho do mercado, com um grau maior de concentração. Portanto, é extremamente importante a relação entre eficiência, concentração e dimensão de mercado. De maneira geral, quanto maior o tamanho mínimo ótimo com relação ao mercado, maior será o grau de concentração da indústria. Não há, deste modo, razões teóricas (econômicas) para a sociedade desejar que as firmas alcancem tamanhos maiores que o mínimo ótimo, embora existam vários incentivos à firmas para assim o fazerem, tais como: controle de mercado, redução da concorrência, poder etc.

Os trabalhos realizados nos Estados Unidos e no Brasil sobre a existência ou não de economias de escala no setor bancário apresentam problemas metodológicos e suas conclusóes parecem pouco confiáveis, embora se possa adiantar, com base nos melhores estudos, que a concentração bancária ocorreu sem que houvesse ganhos significativos de eficiência. ${ }^{3}$

\subsection{Aspectos da política de concentração bancária brasileira}

O pós-II Guerra foi caracterizado por um crescimento acentuado no número de bancos comerciais e que se estabilizou em meados dos anos 50. A partir daí o crescimen to do sistema bancário deu-se basicamente pela abe rtura de agên cias.

Por te r sido considerado elevado o número de ban$\cos \mathrm{e}$ instável a situação econômica-financeira de bom número de agências, foram acionados pelo Governo federal, a partir de 1964/65, alguns mecanismos que visavam concentrar e estabilizar o sistema bancário. Por outro lado, as políticas de fusões e incorporaçð̃es só foram clara ou explicitamente incentivadas a partir de 1971, com a criação da Cofie. É oportuno lembrar que estas fusōes e incorporaçðes, segundo a legislação, podiam-se fazer entre e interempresas dos setores industriais e financeiros. 
Como se observa, não era apenas uma ou duas variáveis que atuavam no sentido de concentrar o setor bancário. $\mathrm{Na}$ realidade, existia um mecanismo, a partir de um conjunto de variáveis, que produzia tal resultado.

Assim, apresentam-se a seguir as principais variáveis que estavam atuando sobre a estrutura do sistema bancário brasileiro no período pós-1967 - a partir do qual estão presentes a maior parte delas - e que, juntamente com fatores aleatórios descritos por Gibrat (1931), devem ser responsabilizados pelo processo de concentração ocorrido. A evidência empírica dessa concentração será vista no item 3 .

a) Controle de cartas patentes: tem o mesmo efeito que as barreiras à entrada na indústria, devendo, portanto, suportar boa parcela de responsabilidade pela concentração; para isso, bastaria que ocorressem pelo menos taxas diferenciadas de crescimento entre bancos. Cabe mais uma observação sobre o modelo de Gibrat: ele observou que, mesmo que por fatores puramente ale atórios caiam taxas de crescimento diferentes para as dife rentes firmas, ainda assim a estrutura industrial estará sujeita a um processo de concentração.

b) Mercado de cartas patentes: uma força complementar ao controle de cartas patentes, dentro do leque de regulaçőes governamentais sobre o sistema bancário, foi a permissão para compra e venda das cartas patentes nas mãos do setor privado. Assim, congeladas as concessões de novas cartas, na realidade criou-se um mercado de cartas patentes e sua venda transformou-se num bom negócio para aqueles banqueiros malsucedidos em suas ativid ades.

c) Pode-se agregar num único item: 1. tabelamento do preço do principal produto dos bancos - taxa de juros que funcionou, a partir de 1967, como um "preço de eliminação", uma vez que prejudicava os bancos deficitários e que apresentavam custos elevados, resultado de um crescimento desordenado. Isso se deu a despeito das reciprocidades para aumentar as receitas e compensar o tabelamento; 2 . a remuneração nominal igual a zero dos depósitos bancários à vista, que desencadeou um processo de competição caracterizada pela diferenciação dos serviços - abertura de agências luxuosas, postos de serviços etc.; 3. a taxa de inflação, que tornava negativa a remune ração real dos depósitos à vista, principal fonte de serviços dos bancos comerciais, na época. Daí a corrida para a abertura descontrolada de agências.

Esses três pontos representaram grande incentivo ao crescimento dos bancos, que, limitado pelo item $a$ e possibilitado pelo segundo, fez-se necessariamente pela diminuição do número deles.

d) Exigências de certo volume de capital relativamente aos depósitos. Esta exigência era importante, uma vez que favorecia dos bancos maiores (em capital), possibilitando-lhes maior captação de depósitos, a mais importante fonte de receitas para os bancos, antes de 1974/75.

e) Exigências de índices de imobilização cada vez menores, juntamente com o tabelamento dos juros das operações ativas, constituiu-se, para muitos bancos, num ra: zoável incentivo para diversificação dos seus investimentos e isto con tribuiu sobremaneira para a conglome ração. ${ }^{4}$

f) Vantagens e possibilidades abertas à criação de bancos nacionais, principalmente através de abertura de agências pioneiras, foram francamente favoráveis aos grandes bancos que saiam das praças concentradas e se dirijam para $o$ interior, concorrendo diretamente com pequenos bancos locais ou regionais. 5

g) Variações nas taxas de lucro dos bancos por tamanho. Bouzan (1972) calculou para o ano de 1971 as taxas de lucro dos bancos e seus respectivos desvios-padrões e observou que existe uma correlação negativa entre tama. nho dos bancos e desvio-padrão de suas taxas de crescimento. Este ponto deve ser visto, se não como fator de aumen to do grau de concentração, mas pelo menos como fator de manutenção dos mesmos, pois, uma vez que um banco pequeno passa para um grupo dos grandes, ao que parece por essa evidência, poucas chances tem de voltar ao grupo inferior. ${ }^{6}$

h) Afora todos esses fatores institucionais, que devem ter atuado no sentido de "empurrar" o grau de concentração para cima, deve-se acrescentar as políticas explícitas de incentivos à fusão e incorporação de bancos, que foram bastante acen tuadas no ano de 1971 .

Pelo que se expôs, pode-se concluir facilmente que, em acréscimo ao modelo de Gibrat (1931), o conjunto desses pontos, atuando simultânea e dinamicamente sobre a estrutura de mercado deve, sem dúvida, assumir as responsabilidades pelo processo de concentração verificado no sistema bancário brasileiro. Parece também igualmente verdadeiro que, mesmo na ausência de políticas explícitas de concentração (item $h$ ), existiam elementos suficientemente fortes, além daqueles inerentes ao processo de acumulação de capital, para induzir o aumento da concentração no setor bancário, embora o fizessem a um prazo mais longo.?

No item 3 será apresentada a evidência empírica dos efeitos desse mecanismo que resultou no aumento do grau de concentração do setor bancário brasileiro.

\section{EVIDENCIA EMPIRICA DA CONCENTRAÇÃO}

Os dados que aqui se apresentam objetivam mostrar que o grau de concentração do setor bancário brasileiro elevou-se consideravelmente a partir de 1967, quando se intensificaram os efeitos do mecanismo descrito no item anterior.

\section{I Número de bancos}

Na tabela 1 , pode-se ver que o núme ro de sedes e agências, em 1956, e ram 403 e 3.714 respectivamente, e esses números atingiram os níveis de 262 e 7.060 , em 1967 , 114 e 7.139 , em 1973, e 110 e 10.926 , em 1981. Ou seja, entre 1956/67 (12 anos) desapareceram 141 bancose ampliou-se o número de agências em mais de 3.300. Entre $1967 / 73$ (6 anos) mais 148 bancos deixaram o mercado e o núme ro de agências praticamente se estabilizoù em tomo de 7.100. No último período, 1973/81, o nú- 
Tabela 1

Bancos comerciais e Banco do Brasil: distribuição de dependências - 1956-81

\begin{tabular}{|c|c|c|c|c|c|c|}
\hline \multirow{2}{*}{ Anos } & \multicolumn{3}{|c|}{ Bancos comerciais } & \multirow{2}{*}{ Banco do Brasil } & \multirow{2}{*}{ Total } & \multirow{2}{*}{$\begin{array}{l}\text { Média } \\
(3) /(1) \\
\end{array}$} \\
\hline & $\begin{array}{c}\text { Sede }^{a} \\
(1) \\
\end{array}$ & $\begin{array}{c}\text { Agências } \\
\text { (2) }\end{array}$ & $\begin{array}{c}\text { Total } \\
(1)+(2) \\
\end{array}$ & & & \\
\hline 1956 & 403 & 3.714 & 4.117 & 362 & 4.479 & 10 \\
\hline 1967 & 262 & 7.060 & 7.322 & 697 & 8.019 & 28 \\
\hline 1973 & 114 & 7.139 & 7.253 & 793 & 8.046 & 64 \\
\hline 1981 & 110 & 10.926 & 11.036 & 1.271 & 12.307 & 100 \\
\hline
\end{tabular}

Fonte: Banco Central do Brasil, Conjuntura Econômica-FGV e Banco do Brasil.

(a) Inclui as sedes de representação dos bancos estrangeiros.

(b) Inclui as agências dos bancos estrangeiros.

mero de bancos se estabilizou e o número de agências cresceu em 3.800 aproximadamente. Este crescimento foi intensificado em $1976 .^{\circ}$

A redução do número de sedes dos bancos, conforme mostra a tabela 1 , dever se r vista tomando-se em con. ta o aumento da monetização da economia. Esse aumento, que representa em última análise uma expansão do sistema bancário, em face do uso intenso da moeda escritural nas transaçðes correntes, deu-se com a redução do número de bancos.

\subsection{Tamanho dos bancos}

O tamanho dos bancos que permaneceram ou surgiram no período 1965-81, em termos de número de agências, pode ser visto na tabela 2 .

Como se observa nos dados da tabela 2 , os bancos comerciais privados aumentaram muito, quase três vezes, o número de suas agências entre 1968 e 1981. Mesmo no período em que estava congelada a abertura de agências - 1970-76 - houve um aumento dos bancos, medido pelo número de agências. Isto se deu, em parte, pela diminuição do número de sedes, vendidas ou incorporadas juntamente com suas agências. $O$ tamanho dos bancos comerciais, exceto o Banco do Brasil, medido pelo número de agências, aumentou de maneira relativamente

Tabela 2

Média de número de agências por bancos: $1965-81^{1}$

\begin{tabular}{|c|c|c|c|c|}
\hline \multirow{2}{*}{ Anos } & \multicolumn{2}{|c|}{ Bancos comerciais privados } & \multicolumn{2}{|c|}{ Bancos comerciais $^{2}$} \\
\hline & Total & Quatro maiores $\left(4^{+}\right)$ & Total & Quatro maiores $\left(4^{+}\right)$ \\
\hline 1965 & - & $254(219)$ & 20 & $215(188)$ \\
\hline 1968 & 31 & $315(279)$ & 33 & $259(221)$ \\
\hline 1973 & 65 & $494(383)$ & 64 & $482(396)$ \\
\hline 1981 & 94 & $809(682)$ & 1004 & $796(681)$ \\
\hline
\end{tabular}

Fonte: Banco Central do Brasil $\mathrm{e}$ anexos às demonstraçōes financeiras dos bancos.

${ }^{1}$ Os números entre parênteses referem-se à média dos sete maiores $\left(7^{+}\right)$.

2 Exceto Banco do Brasil. mais rápida, embora os maiores $\left(4^{+}\right.$e $\left.7^{+}\right)$tenham, em média, menos agências do que quando se considera apenas os bancos comerciais privados. ${ }^{9}$

\subsection{Outras medidas de concentrafão ${ }^{10}$}

Existem vários índices para medir a concentração. Entre eles destacam-se: as razões de concentração, os índices de Herfindahl, de Rosenbluth, de Horvath e de Entropia. Muitos estudos foram feitos como forma de mostrar a superioridade e/ou igualdade entre esses indices e uma interessante conclusão é a de Bayley e Boyle (1971), segundo a qual existe uma elevada correlação entre os diversos índices utilizados para medir concentração, não havendo, portanto, superioridade de um com relação aos outros; ademais, a distribuição de núme ro e tamanho das firmas individuais parece não afetar materialmente os resultados obtidos.

Assim, dentre o conjunto existente de medidas de concentração, as razões de concentração - parcela das maiores firmas no mercado - acabam sendo as mais utilizadas, porque "not only are the analy tical results obtained using this variable equal to or superior to any other which might be suggested, in terms of predictive ability, but to researchers they constitute an almost 'free good" ". ${ }^{11}$

Dadas estas considerações, optou-se por utilizar as razões de concentração para representar a medida de concen tração. Assim, elas serão aplicadas às três variáveis que funcionarão como proxy do tamanho dos bancos, quais sejam, depósitos totais, empréstimos e recursos próprios. Decidiu-se trabalhar, para os cálculos das razões de concentração, com os conjuntos dos sete, quatro e um maiores bancos.

a) Bancos comerciais privados

Inicialmente será analisada a concentração dos bancos comerciais privados. Por limitação de informação, o período ficou restrito a 1968-81. ${ }^{12}$ Apesar de algumas mudanças na forma de apresentação dos demonstrativos financeiros, os dados são relativamente comparáveis, principalmente os de empréstimos e depósitos. ${ }^{13}$ A tabela 3 apresenta essas in formaçōes.

Observa-se que entre 1968/71, a participação do maior e dos 4 e 7 maiores bancos come rciais privados no total do setor bancário privado foi apenas ligeiramen- 
Tabela 3

Participação dos maiores bancos comerciais privados no sistema bancário privado: depósitos, empréstimos e recursos próprios - $1968-81^{1}$

(Em Cr\$ milhões)

\begin{tabular}{|c|c|c|c|}
\hline \multirow{2}{*}{ Bancos } & \multicolumn{3}{|c|}{1968} \\
\hline & Depósitos & Emprést. & Rec. próprios \\
\hline Maior & 1.011 & 667 & 142 \\
\hline Quatro maiores & 2.750 & 1.821 & 333 \\
\hline Sete maiores & 4.020 & 2.639 & 511 \\
\hline Total & 11.054 & 8.643 & 1.833 \\
\hline Maior/total & 0,09 & 0,08 & 0,09 \\
\hline Quatro maiores/total & 0,25 & 0,21 & 0,18 \\
\hline Sete maiores/total & 0,36 & 0,31 & 0,28 \\
\hline \multirow{2}{*}{ Bancos } & \multicolumn{3}{|c|}{1971} \\
\hline & Depósitos & Emprést. & Rec. próprios \\
\hline Maior & 2.310 & 1.949 & 451 \\
\hline Quatro maiores & 7.521 & 6.016 & 1.072 \\
\hline Sete maiores & 10.364 & 8.414 & 1.580 \\
\hline Total & 25.286 & 25.099 & 5.073 \\
\hline Maior/total & 0,09 & 0,08 & 0,09 \\
\hline Quatro maiores/total & 0,30 & 0,24 & 0,21 \\
\hline Sete maiores/total & 0,41 & 0,34 & 0,31 \\
\hline
\end{tabular}

1973

\begin{tabular}{lccc} 
& & & \\
\cline { 2 - 4 } Bancos & Depósitos & Emprést. & Rec. próprios \\
\hline Maior & 6.639 & 5.805 & 1.048 \\
Quatro maiores & 16.170 & 14.162 & 2.320 \\
Sete maiores & 23.437 & 20.463 & 3.457 \\
Total & 51.441 & 50.984 & 9.554 \\
Maior/total & 0,13 & 0,11 & 0,11 \\
Quatro maiores/toral & 0,31 & 0,28 & 0,24 \\
Sete maiores/total & 0,46 & 0,40 & 0,36 \\
\hline
\end{tabular}

\begin{tabular}{lccc}
\hline \multirow{4}{*}{ Bancos } & \multicolumn{4}{c}{1975} \\
\cline { 2 - 4 } & Depósitos & Emprést. & Rec. próprios \\
\hline Maior & 15.422 & 15.789 & 2.203 \\
Quatro maiores & 38.865 & 39.201 & 5.294 \\
Sete maiores & 53.819 & 54.964 & 7.586 \\
Total & 95.501 & 106.055 & 17.554 \\
Maior/total & 0,16 & 0,15 & 0,13 \\
Quatro maiores/total & 0,41 & 0,37 & 0,30 \\
Sete maiores/total & 0,56 & 0,52 & 0,43 \\
\hline
\end{tabular}

te crescente com relação às três variáveis escolhidas: depósitos, empréstimos e recursos próprios. Apesar de se comportar desta forma no período, como se comprovará pela tabela 4, este valor já é bastante elevado relativamente aos anos anteriores.
1980

\begin{tabular}{|c|c|c|c|}
\hline \multirow{2}{*}{ Bancos } & \multirow[b]{2}{*}{ Depósitos } & \\
\hline & & Emprést. & Rec. próprios \\
\hline Maior & 150.982 & 93.931 & 29.213 \\
\hline Quatro maiores & 359.265 & 231.138 & 53.640 \\
\hline Sete maiores & 484.687 & 338.539 & 70.563 \\
\hline Total & 878.642 & 1.121 .921 & 221.093 \\
\hline Maior/total & \multicolumn{2}{|c|}{$0,17 \quad 0,08$} & $\quad 0,13$ \\
\hline Quatro maiores/total & \multicolumn{2}{|c|}{0,41} & 0,24 \\
\hline Sete maiores/total & \multicolumn{2}{|c|}{0,55} & 0,32 \\
\hline \multirow{2}{*}{ Bancos } & \multicolumn{3}{|c|}{1981} \\
\hline & Depósitos & Emprést. & Rec. próprios \\
\hline Maior & 274.585 & 209.107 & 65.383 \\
\hline Quatro mariores & 675.805 & 516.252 & 119.306 \\
\hline Sete maiores & 927.984 & 732.877 & 164.072 \\
\hline Total & 1.418 .143 & 2.253 .508 & 421.192 \\
\hline Maior/total & \multicolumn{2}{|c|}{$\begin{array}{ll}0,19 & 0.09\end{array}$} & 0,16 \\
\hline Quatro maiores/total & 0,48 & 0,23 & 0,28 \\
\hline Sete mariores/total & \multicolumn{2}{|c|}{0,65} & 0,39 \\
\hline
\end{tabular}

Fonte: linha total: Banco Central;

demais linhas: demonstrações financeiras dos bancos.

1 Bancos classificados por ordem de depósitos totais de cada ano.

2 Total refere-se ao mës de novembro de 1981.

A partir de 1971 até 1975 , a parcela dos maiores $\left(1^{+}, 4^{+}\right.$e $\left.7^{+}\right)$, em termos de depósitos, cresceu e chegou neste último ano a atingir um nível bastante expressivo. Enquan to isso, a apropriação dos empréstimos e recursos próprios por estes bancos também foi crescente, e os niveis atingidos foram igualmente elevados.

Entre 1975 e 1981, a concentração teve comportamento diferente para cada uma das variáveis utilizadas. Medida pela apropriação dos depósitos, os maiores bancos mantiveram sua parcela até 1980 e apresentaram, em 1981, elevado nivel, superando a marca alcançada em $1976 .{ }^{14}$ Quanto aos empréstimos, foi bastante acentuado o declínio da parcela de todos os três conjuntos $\left(1^{+}, 4^{+}\right.$e $\left.7^{+}\right)$, atingindo em 1980 pouco mais de $50 \%$ de seu nível mais elevado, em 1975. Este declínio deve ser compreendido à luz da recomposição dos ativos dos bancos, que ocorreu em meados dos anos 70 , quando foi ampliada a parcela das operações cambiais nos ativos totais dos bancos. E fato conhecido de todos que esse tipo de operação é privilégio, em boa medida, dos grandes bancos. No que se refere ao comportamento da concentração, medido por recursos próprios, observa-se que ela sofreu um declínio no período, porém menos acentuado do que quando medido pelos empréstimos.

A tabela 4 apresenta a evolução do grau de concentração no sistema bancário nacional - incluindo os bancos privados e oficiais, com exceção do Banco do Brasil. De maneira geral, percebe-se um comportamento mais ou menos idêntico àquele mostrado na tabela anterior. É, no entanto, considerado aqui um período mais amplo, que permite visualizar melhor a tranformação ocorrida na estrutura da indústria bancária em termos de concen- 
Tabela 4

Participação dos maiores bancos comerciais no sistema bancário:1 depósitos, empréstimos e recursos próprios $1965-81^{2}$

(Em Cr\$ milhoes)

\begin{tabular}{|c|c|c|c|}
\hline \multirow{2}{*}{ Bancos } & \multicolumn{3}{|c|}{1965} \\
\hline & Depósitos & Emprést. & Rec. próprios \\
\hline Maior & 271 & 176 & 39 \\
\hline Quatro maiores & 969 & 622 & 105 \\
\hline Sete maiores & 1.585 & 1.111 & 202 \\
\hline Total & 6.042 & 3.986 & 995 \\
\hline Maior/total & 0,04 & 0,04 & 0,04 \\
\hline Quatro maiores/tótal & 0,16 & 0,16 & 0,11 \\
\hline Sete maiores/total & 0,26 & 0,28 & 0,20 \\
\hline \multirow{2}{*}{ Bancos } & \multicolumn{3}{|c|}{1967} \\
\hline & Depósitos & Emprést. & Rec. próprios \\
\hline Maior & 723 & 629 & 102 \\
\hline Quatro maiores & 2.290 & 1.814 & 376 \\
\hline Sete maiores & 3.317 & 2.544 & 543 \\
\hline Total & 10.928 & 8.616 & 2.073 \\
\hline Maior/total & 0,07 & 0,07 & 0,05 \\
\hline Quatro maiores/total & 0,21 & 0,21 & 0,18 \\
\hline Sete maiores/total & 0,30 & 0,30 & 0,26 \\
\hline
\end{tabular}

\begin{tabular}{lrrr}
\hline & \multicolumn{3}{c}{1971} \\
\cline { 2 - 4 } & Depósitos & Emprést. & Rec. próprios \\
\hline Maior & 2.604 & 3.174 & 622 \\
Quatro maiores & 8.596 & 7.929 & 1.470 \\
Sete maiores & 12.424 & 12.409 & 2.432 \\
Total & 34.077 & 37.762 & 8.073 \\
Maior/total & 0,08 & 0,08 & 0,08 \\
Quatro maiores/total & 0,25 & 0,21 & 0,18 \\
Scte maiores/total & 0,36 & 0,33 & 0,30 \\
\hline
\end{tabular}

\begin{tabular}{lcrr}
\hline & \multicolumn{4}{c}{1974} \\
\cline { 2 - 4 } & Depósitos & Emprést. & Rec. próprios \\
\cline { 2 - 4 } & 10.378 & 12.059 & 1.382 \\
Maior & 32.376 & 33.602 & 4.599 \\
Quatro maiores & 42.826 & 45.297 & 6.188 \\
Sete maiores & 93.978 & 114.698 & 19.752 \\
Total & 0,11 & 0,11 & 0,07 \\
Maior/total & 0,34 & 0,29 & 0,23 \\
Quatro maiores/total & 0,46 & 0,39 & 0,31 \\
Sete maiores/total & & & \\
\hline
\end{tabular}

tração. A tendência, portanto, é mais ou menos a mesma, mas evidentemente os valores absolutos são menores, uma vez que os bancos oficiais incrementam mais os denominadores do que os numeradores das razões de concentração - normalmente apenas um banco oficial,
1976

Bancos

Depósitos Emprést. Rec. próprios

\begin{tabular}{lrrr}
\hline Maior & 22.123 & 20.937 & 3.720 \\
Quatro maiores & 58.585 & 73.207 & 9.207 \\
Sete maiores & 84.434 & 100.928 & 12.742 \\
Total & 182.471 & 264.002 & 44.246 \\
Maior/total & 0,12 & 0,08 & 0,08 \\
Quatro maiores/total & 0,32 & 0,20 & 0,21 \\
Sete maiores/total & 0,46 & 0,38 & 0,29 \\
\hline
\end{tabular}

1980

Bancos

Depósitos Emprést. Rec. próprios

\begin{tabular}{|c|c|c|c|}
\hline Maior & 150.982 & 93.911 & 29.213 \\
\hline Quatro majores & 380.720 & 277.058 & 62.272 \\
\hline Sete maiores & 541.876 & 385.336 & 76.471 \\
\hline Total & 1.200 .909 & 1.906 .856 & 306.243 \\
\hline Maior/total & 0,13 & $3 \quad 0,05$ & 0,10 \\
\hline Quatro maiores/total & 0,32 & 0,15 & 0,20 \\
\hline Sete maiores/total & 0,45 & 0,20 & 0,25 \\
\hline
\end{tabular}

\begin{tabular}{|c|c|c|c|c|}
\hline \multirow{2}{*}{ Bancos } & \multicolumn{4}{|c|}{1981} \\
\hline & Depósitos & Emprést. & & ec. próprios \\
\hline Maior & 274.585 & 209.107 & & 65.383 \\
\hline Quatro maiores & 751.022 & 540.705 & & 131.159 \\
\hline Sete maiores & 1.086 .293 & 799.758 & & 168.441 \\
\hline Total & 1.963 .572 & 1.837 .245 & & 577.872 \\
\hline Maior/total & 0 , & & 0,05 & 0,11 \\
\hline Quatro maiores/total & 0 , & & 0,14 & 0,23 \\
\hline Sete maiores/total & 0 & 55 & 0,21 & 0,29 \\
\hline
\end{tabular}

Fonte: linha total - Banco Central; demais linhas- - demonstracões financeiras dos bancos.

Exceção do Banco do Brasil.

2 Bancos classificados por ordem de depósitos totais de cada ano.

3 Total refere-se ao mês de novembro de 1981.

Banespa, entra na lista dos sete maiores. No início e no fim do período teve-se a presença também do Bane rj e até 1971 a do BNB.

Tavares (1983) apresenta uma evidência de que na evolução dos números de bancos (sedes) a maior variação deles deu-se por causa dos bancos privados, ou seja, as principais transformações no setor se de ram via bancos privados. Assim, quando se adicionam os bancos oficiais aos privados como na tabela 4 , observa-se que o crescimento da concentração torna-se mais lento, embora contínuo até 1974 , do que quando se considerava apen as o conjunto de bancos privados, como foi visto na tabela 3. Desta forma, não fica muito clara a demarcação de fases na evolução da concentração, uma vez que a elevação torna-se mais suave.

No en tanto, é perceptível que, medida em termos de controle sobre os depósitos, a concentração elevou-se continuamente de 1965-74. A partir de então, mantevese constante até 1980 , quando em 1981 voltou a incre- 
mentar-se e, desta vez, em nível superior ao seu pico, 1974.

A concentarção medida pela participação nos empréstimos foi crescente de 1965 até 1974, quando alcançou seu nível mais elevado. A partir de 1976, porém, este indicador decresceu rapidamente, atingindo em 1980 aproximadamente $50 \%$ do seu valor no ano de pico, 1974. Mais uma vez, acredita-se que essa "desconcentração", verificada a partir de 1976 , deve ser entendida à luz das mudanças na composição dos ativos dos grandes bancos, na direção de maior participação das ope rações cambiais.

Quanto à medida referida pelos recursos próprios, mostrou um comportamento ascendente, porém lento, até 1974. A partir daí, manteve-se razoavelmente estável até 1981, para os três grupos estudados.

Para finalizar, pode-se tirar como principais conclusões, das tabelas 3 e 4 , que:

a) a magnitude dos índices de concentração medida pela parcela controlada por qualquer dos três conjuntos de bancos com relação às variáveis depósitos e recu rsos próprios foi crescente até $1974 / 75$ e manteve-se estável no restante do período; para a variável empréstimos, a concentração acentuou-se até por volta de 1974, tornandose decrescente a partir deste ano; ${ }^{15}$

b) a evidência do aumen to da concen tração entre 1967-71 pode ser vista como uma confirmação da hipótese de que o tabelamen to dos juros e determinado conjunto de politicas, descrito no item anterior, embora não diretamente voltadas para concentrar o sistema bancário, acabaram por produzir este resultado, com a redução dos juros (tabelamento a partir de 1967), sendo causa e nao conseqüência da concentração do setor. ${ }^{16}$ Ademais, os dados dessas tabelas confirmam também que as políticas de fusões e incorporaçōes propriamente ditas tiveram total êxito em aumentar a grande concentração no setor a partir de 1971.

c) mesmo não se comparando, até aqui, com dados de outras estruturas de mercado, pode-se afirmar, desde logo, que o nível de concentração do setor bancário é elevado, mormente quando medido pelos depósitos totais.

\subsection{Comparação da concentração bancária no México e Brasil ${ }^{17}$}

Para melhor qualificar os índices de concentração encontrados, vai-se, agora, submetê-los a uma confrontação com os mesmos índices para o caso mexicano, utilizando-se a variável ativos totais.

A comparação com a estrutura bancária mexicana é bastante interessante, uma vez que o grau de seu desenvolvimento e sua estrutura produtiva são muito semelhantes aos do Brasil.

A estrutura da indústria bancária mexicana em termos de instituições e regulação não difere muito da brasileira. Os bancos comerciais sæoo geralmente bancos de depósitos e sujeitos à regulação do Banco do México (banco central). Os bancos mexicanos, desde a década de 50 , vêm expandindo seu número de agências por todo o território do país. No entanto, alguns bancos preferem adotar a estratégia de ter uma rede de bancos afiliados, como é o exemplo do Banco de Comércio S.A., que possuía, em 1975, 34 bancos afiliados, constituindo o sistema de Banco de Comércio.

Os dados apresentados na tabela 5, sobre o México, foram retirados de Eckaus (1975). Dada a dificuldade de distinguir quem controla o sistema de Banco de Comércio, o autor trata esses bancos de duas formas: como sendo um único banco (agregando-os) e como sendo vários bancos (separando-os).

Como se pode ver, na tabela 5, o grupo dos quatro maiores bancos no México detinha, em 1970, pouco mais da metade dos ativos dos bancos mexicanos, tomando os Bancos de Comércio separadamente. Quando eles são levados em conta conjuntamente, como um único banco, observa-se que a percentagem é 17 pontos mais elevada e apenas os dois maiores detêm parcela semelhante àquela dos quatro maiores, quando se trata separadamente os Bancos de Comércio. A parcela dos 10 maiores, agregando-se os Bancos de Comércio, atingiu a marca dos $80 \%$, sendo apenas $20 \%$ dos ativos controlados pelo restante. Quando os Bancos de Comércio são desagregados, a parcela daqueles, 10 maiores, reduz-se a aproximadamente $65 \%$, sobrando $35 \%$ do total dos ativos para o controle dos demais bancos.

Observa-se claramente que a estrutura bancária mexican a é, além de concentrada, bastante desigual entre o próprio grupo dos maiores: os quatro maiores detinham $70 \%$ dos ativos e os seis seguintes, apenas $10 \%$, em 1970 , ou separando-se os Bancos de Comércio, os quatro maiores detêm $53 \%$ e os seis seguintes, apenas $11 \%$. Isto dá, é claro, um caráter mais agudo à concentração.

Quando se compara com dados para o Brasil, verifica-se que aqui os 10 maiores constituem um conjunto bem mais homogêneo que no caso mexicano. Assim, quando se compara apenas o grupo dos quatro maiores, excluindo o Banco do Brasil, como o sistem a mexicano, tomando os Bancos de Comércio separadamente, vê-se que é bem mais elevado o controle dos ativos pelos,maiores bancos mexicanos. No entanto, quando se observa o grupo dos 10 maiores, novamente excluindo o Banco do Brasil e separando os Bancos de Comércio, vê-se que há maior aproximação dos índices mexicanos e nacionais.

Quando se levam em conta os Bancos de Comércio, conjuntamente, no caso do México, e considera-se o Banco do Brasil, no caso do Brasil, observa-se que há razoável semelhança entre a concentração da indústria bancária mexicana e a brasileira. Neste caso, a estrutu ra do sistema bancário brasileiro fica tão desigual entre o primeiro grupo, quatro maiores, quanto a mexican a e, assim, para os dois principais grupos, quatro maiores e dez maiores, a concen tração da estrutura bancária brasileira é aproximadamente $64 \%$ daquela verificada no México em $1970 .^{18}$

Analisando os demais dados da tabela 5, nota-se que a concentração bancária no México sofreu um relativo declínio nos 30 anos analisados por Eckaus, como ele próprio afirma. ${ }^{19}$ No caso brasileiro, quando não se leva em conta o Banco do Brasil, o grau de concentração da estrutura bancária foi mais ou menos estável entre $1960 / 70$, e razoavelmente crescente na década de $70 .^{20}$ 
Tabela 5

Participaçæo dos maiores bancos no México e no Brasil, por ativos totais:" $1940,1949,1960,1970$ e $1980^{2}$

\begin{tabular}{|c|c|c|c|c|c|c|c|}
\hline \multirow{2}{*}{ Bancos } & \multicolumn{4}{|c|}{ México } & \multicolumn{3}{|c|}{ Brasil } \\
\hline & 1940. & 1949 & 1960 & 1970 & 1960 & $1970^{\circ}$ & $1980^{\circ}$ \\
\hline \multirow[t]{2}{*}{1 e 2} & 0,5646 & 0,4445 & 0,3818 & 0,3895 & 0,1146 & 0,1084 & 0,1405 \\
\hline & $(0,6651)$ & $(0,5430)$ & $(0,5330)$ & $(0,5571)$ & $(0,6003)$ & $(0,3391)$ & $(0,4957)$ \\
\hline \multirow[t]{2}{*}{3 e 4} & 0,1395 & 0,1118 & 0,1374 & 0,1380 & 0,0803 & 0,0678 & 0,1902 \\
\hline & $(0,1589)$ & $(0,1118)$ & $(0,1374)$ & $(0,1382)$ & $(0,0401)$ & $(0,0536)$ & $(0,1093)$ \\
\hline \multirow[t]{2}{*}{ Total de 1 a 4} & 0,7041 & 0,5563 & 0,5192 & 0,5276 & 0,1948 & 0,1762 & 0,3307 \\
\hline & $(0,8240)$ & $(0,6548)$ & $(0,6704)$ & $(0,6953)$ & $(0,6405)$ & $(0,3928)$ & $(0,6049)$ \\
\hline \multirow[t]{2}{*}{$5 e 6$} & 0,0697 & 0,0749 & 0,0864 & 0,0497 & 0,0581 & 0,0618 & 0,0816 \\
\hline & $(0,0794)$ & $(0,0749)$ & $(0,0864)$ & $(0,0498)$ & $(0,0300)$ & $(0,0441)$ & $(0,0512)$ \\
\hline \multirow[t]{2}{*}{$7 \times 10$} & 0,0574 & 0,0913 & 0,0639 & 0,0673 & 0,0922 & 0,0930 & 0,1281 \\
\hline & $(0,0612)$ & $(0,0733)$ & $(0,0541)$ & $(0,0603)$ & $(0,0436)$ & $(0,0754)$ & $(0,0774)$ \\
\hline \multirow[t]{2}{*}{ Total de 1 a 10} & 0,8312 & 0,7225 & 0,6695 & 0,6446 & 0,3452 & 0,3310 & 0,5403 \\
\hline & $(0,9646)$ & $(0,8030)$ & $(0,8109)$ & $(0,8054)$ & $(0,7140)$ & $(0,5122)$ & $(0,7335)$ \\
\hline \multirow[t]{2}{*}{11 a 20} & $0 ; 0845$ & 0,1178 & 0,1035 & 0,1092 & 0,1607 & 0,1661 & 0,2793 \\
\hline & $(0,0354)$ & $(0,0958)$ & $(0,0877)$ & $(0,0898)$ & $(0,0705)$ & $(0,1220)$ & $(0,1477)$ \\
\hline \multirow[t]{2}{*}{ Total de 1 a 20} & 0,9157 & 0,8403 & 0,7730 & 0,7528 & 0,5059 & 0,4972 & 0,8196 \\
\hline & $\leq=$ & $(0,8988)$ & $(0,8986)$ & $(0,8952)$ & $(0,7845)$ & $(0 ; 6342)$ & $(0.8812)$ \\
\hline \multirow[t]{2}{*}{ Bancos restantes } & 0,0844 & 0,1597 & 0,2269 & 0,2462 & 0,4941 & 0,5028 & 0,1804 \\
\hline & 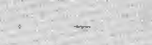 & $(0,1012)$ & $(0,1013)$ & $(0,1049)$ & $(0,2155)$ & $(0,3658)$ & $(0,1188)$ \\
\hline
\end{tabular}

Fonte: Arutário financeiro do México; demonstraçóes financeiras publicadas; Baneo Céntral do Brasil e Movimento bancário do Brasil: 1960 e 1970.

Os bancos no Brasil foram classificados por depósitos em cada ano, tomando-se depois os valores de seus ativos.

${ }^{2}$ Os números entre parênteses representam para o México a agregação de todos os Bancos de Comércio (considerados como sendo um único banco); para o Brasil significam a inclusāo do Banco do Brasil. Os dados referentes ao México foram retirados de Eckaus (1975).

Da comparação do sistema bancário mexicano e do brasileiro, pode-se concluir que: a) na década de 70 , a estrutura bancária brasileira foi marcada por tendência inversa daquela apresentada no México de 1940/70. Lá os pequenos bancos ganharam posições relativas, enquanto aqui ocorreu exatamente o contrário; b) no que diz respeito ao grau de concentração, o primeiro sistema tem um nivel elevado, enquanto o segundo não se situa muito distante deste.

Embora se tenha trabalhado nesta comparação com dados sobre os ativos bancários, acredita-se que a conclusão anterior pode ser, sem nenhuma restrição, extrapolada para o cálculo realizado com as variáveis depósitos, empréstimos e recursos próprios, conforme foi feito anteriomente. ${ }^{21}$

\section{CONSIDERAÇÕES FINAIS}

Até aqui se mostrou que existem razões teóricas, do ponto de vista estritamente econômico, para se desejar a concentração, representada pelo aumento do tamanho das plantas das firmas. Da mesma forma, foi apresentado um mecanismo no qual se explicitam as variáveis que atuaram sobre o sistema bancário brasileiro, a partir de 1967, no sentido de favorecer a concentração neste setor.

Foi sugerido que aquelas variáveis, presentes a partir de $1964 / 65$, atuando simultaneamente e dinamicamente, seriam capazes de desencadear um processo de concentração no setor bancário. A partir de 1971 outras medidas foram adotadas, por parte das autoridades econômicas, no sentido de incrementar tal processo que já se havia iniciado, particularmente a partir de 1967 com o tabelamento dos ju ros.

Para qualificar os efeitos do mecanismo, que se estabeleceu com a presença daquelas variáveis, sobre a estrutura do setor bancário brasileiro, foram escolhidos vários métodos com dife rentes variáveis chegando às seguin tes conclusŏes:

Observou-se que vários fatores que funcionam como incentivo à concentração estavam atuando sobre a estrutura de mercado da indústria bancária desde 1964/65. Esses fatores, mesmo na ausência de políticas explícitas de concentraçāo, adotadas em 1971, tiveram papel bem definido de conduzir o setor bancário a uma estrutura de me rcado mais concentrada.

Analisando-se diversos indicadores de concentraçāo, chegou-se à conclusão de que a concentração do setor bancário brasileiro é razoavelmente elevada, tendo-se intensificado no período $1971 / 75$. Esta conclusão é fruto da observação do comportamento das razões de concentração - participação dos maiores bancos no total de depósitos, empréstimos, recursos próprios e ativos totais - no período de 1965-81.

Esta conclusão é verdadeira mesmo quando se compara com dados de concentração de outros parses, no 
caso escolhido o México. Essa comparação reforçou a constatação do grau razoavelmente elevado da concentração do setor bancário brasileiro.

Por outro lado, deve-se ressaltar que as medidas de concentração, aqui utilizadas, tendem à subestimar o verdadeiro nível da mesma. Isso se deve ao fato de os bancos comerciais, no Brasil, serem líderes de conglomerados financeiros, o que não foi captado pelos indicadores utilizados neste artigo.

Da mesma forma, é oportuno lembrar que não se teve nenhuma preocupação com os efeitos do poder político-econômico, gerado pelo aumento da concentração, com relação às autoridades monetárias, à dete rmin ação da taxa de ju ros, aos concorrentes, bem como aos demais setores da economia. ${ }^{22}$ Isso, contudo, năo significa que o tema não tenha importância. Ao contrário, acredita-se que a relevância destes e feitos impðe aos pesquisadores uma linha de preocupação que não deve ser deixada à parte.

\footnotetext{
* Este trabalho é parte da dissertação de mestrado do autor, o qual agradece ao Prof. Hélio Nogueira da Cruz por suas sugestões durante a elaboração da mesma.
}

\section{REFERENCIAS BIBLIOGRAFICAS}

Bailey, D. \& Boyle, S.E. Optimal measure of concentration. Joumal of the American Statistical Association, Washington, DC, 66 (336): 702-6, Dec. 1971.

Bain, J.S. Organización industrial. Barcelona, Omega, 1963.

Banco Central do Brasil. Relatórios e boletins, vários nos

Bouzan, A. Os bancos comerciais no Brasil: uma análise do desenvolvimento recente $-1965 / 71$. Tese de doutoramento. São paulo, FEA/USP, 1972.

Braga, H.C. \& Mascolo, J.L. Mensuração da concentração industrial no Brasil. Brasília, ESAF/MF, 1982. (Relatórios de Pesquisa e Notas de Trabalho, n. 1.)

Carvalheiro, N., Bancos comerciais no Brasil - 1964/ 1976: crescimento $\boldsymbol{e}$ concentração. Dissertação de mestrado. São Paulo FEA/USP, 1982.

Carvalho, J.L. Dos custos de se tomar viável a "mão invisível": o caso da intervenção do estado. Revista Brasilei- ra de Economia, Rio de Janeiro, FGV, 31(1):97-130, jan./mar. 1977.

Conjuntura Econômica, Rio de Janeiro, FGV, vários nos

Eckaus, R.S., A estrutura do setor bancário no México, 1940-1970. Revista Brasileira de Mercado de Capitais, Rio de Janeiro, $I$ (2): 22 1-72, maio/ago. 1975.

Fonseca, J.S. \& Sanvicente, A.Z. A concentração do sistema bancário comercial brasileiro. Revista Brasileira de Mercado de Capitais, Rio de Janeiro, 3 (9): 433-55, set./dez. 1977.

Gibrat, R. Les inegalités économiques. Paris, s.c.p., 1931.

Sayad, J. Regulation on Brazilian commercial banks. New Haven, 1976. tese Ph.D, Yale University.

- Controle de juros e saldos médios. Revista Brasileira de Economia, Rio de Janeiro, FGV, 31 (1):.229-48, jan./mar. 1977.

Tavares, Martus A.R. Juros, custos e concentração bancária no Brasil: 1967/76 Dissertação de mestrado. São Paulo, FEA/USP, 1983.

${ }^{1}$ Para um estudo mais amplo da relação entre juros, custos e concentração no setor bancário brasileiro veja Tavares (1983).

${ }^{2}$ Veja Bain (1963), sobre estes aspectos.

${ }^{3}$ Tavares (1983) apresenta uma revisão da literatura sobre economias de escala na atividade bancária.

4 Veja Sayad (1976 e 1977).

5 Sobre isto veja Carvalho (1977).

6 Tavares (1983) observou, numa amostra de 24 bancos no período de 1973 a 80 , que os bancos de maior tamanho apresentam taxas de lucro mais elevadas e mais estáveis do que aqueles de menor porte. Ver cap. 4 .

${ }^{7} \mathrm{Em}$ face do nível de regulação a que estão sujeitos os bancos comerciais e as instituições financeiras em geral, não é clara a evidência de concentração decorrente da Lei de Acumulação de Capital. Daí se ter optado pela análise das variáveis concretas que atuaram sobre o setor bancário provocando um aumento da concentração.

${ }^{8}$ O número de agências ficou congelado entre 1970-76; ver Resolução n. 141 (23 de março de 1970) do Banco Central.

9 Para uma análise mais detalhada e com maiores informaçōes veja Tavares (1983), cap. 4.

${ }^{10}$ Este estudo de concentração refere-se apenas à "concentração absoluta" do setor bancário brasileiro. Em recente trabalho empírico sobre o setor Carvalheiro (1982) utilizou o conceito de "concentração relativa", medindo a desigualdade entre bancos comerciais brasileiros. 
${ }^{11}$ Bayley \& Boyle (1971) p. 706.

12 Para efeito deste trabalho consideraram-se apenas alguns anos. Para uma análise completa do período ver Tavares (1983) cap. 4.

${ }^{13}$ Esta observação, assim como a da nota anterior, é válida para os dados das tabelas 3 e 4 .

14 Os dados de 1981 eśtão ligeiramente superestimados, pois os valores totais das três variáveis são referentes ao mês de novembro de 1981 , tomando, portanto, os denominadores das razões de concentração menores que os efetivos.

15 Trabalhando com os mesmos conjuntos de bancos $\left(1^{+}, 4^{+}\right.$e $\left.7^{+}\right)$ Tavares (1983) mostra que houve também aumento da concentração medida pelo número de agências controladas por esses bancos, no período $1965 / 81$.

${ }^{16}$ Sobre estes pontos ver Tavares (1983) cap. 3 e 4.

${ }^{17}$ Os dados aqui apresentados referem-se ao período anterior à intervenção de 1982, em que o governo mexicano estatizou o sistema bancário privado nacional.
18 Sobre a desigualdade da distribuição dos ativos entre os bancos brasileiros em comparação com México e EUA ver Fonseca \& Sanvicente (1977).

${ }^{19}$ Eckaus, R.S. op. cit. p. 270.

${ }^{20}$ Os dados para 1980 podem estar ligeiramente superestimados, uma vez que o total dos ativos (denominadores das razões de concentração) foi retirado do balancete consolidado dos bancos comerciais publicado pelo Banco Central, que evita a duplicação de algumas contas, tornando, assim, o valor total desses ativos menor com relação à soma direta dos ativos publicados nos balanços dos bancos. Esse fato não compromete, no entanto, a análise do comportamen to relativo dos bancos.

21 Tavares (1983), cap. 4, faz também uma comparação do nível de concentração dos setores banćrío e industrial brasileiro, tendo concluído que o nível de concentração do primeiro é razoavelmente elevado se comparado com uma amostra do setor industrial (quatro dígitos).

${ }^{22}$ Tavares (1983), cap. 4, faz uma breve digressão sobre esta questão.

\section{O Correio da Unesco}

Ano 13, n. 7 , agosto 1985

\section{Quarenta anos depois Comemoração do fim da II Guerra Mundial}

A paz e os valores humanos Amadon - Mahtar M'Bow

Por que a guerra? (Carta a Sigmund Freud) Albert Jinstein

O genocídio começa pela agressão cultural irederick V. Grunfeld

A resistência na gruta de Lascaux Um estranho esconderijo

André Mairawx

Os museus subterrâneos Para salvar as coleções de arte britânicas

Farold Plenderleith
No Ermitage, a arte e a vida continuam O museu soviético durante o cerco de Leningrado

Boris Protravski

Ainda é possivel salvar a civilização?


Turi xirchin

A resistência esquecida

"O som e a fúria"

Um calendário para a paz Giotsu IT. Bato

Emancipação dos homens e dos povos

Unesco: nascimento de um ideal

Do pessimismo à esperanca

Iewis Thomas

O inverno nuclear

As conseqüências para o planeta

Investigações da Unesco sobre a paz

Pedidos à Fundação Cotallio Varfand anora 